\title{
Prevalence of infections among residents of Residential Care Homes for the Elderly in Hong Kong
}

\author{
Carmen SM Choy *, H Chen, Carol SW Yau, Enoch K Hsu, NY Chik, Andrew TY Wong
}

This article was published on $6 \mathrm{Jul}$ 2016 at www.hkmj.org.

\section{A B S T R A C T}

Introduction: A point prevalence study was conducted to study the epidemiology of common infections among residents in Residential Care Homes for the Elderly in Hong Kong and their associated factors.

Methods: Residential Care Homes for the Elderly in Hong Kong were selected by stratified single-stage cluster random sampling. All residents aged 65 years or above from the recruited homes were surveyed. Infections were identified using standardised definitions. Demographic and health informationincluding medical history, immunisation record, antibiotic use, and activities of daily living (as measured by Barthel Index) - was collected by a survey team to determine any associated factors.

Results: Data were collected from 3857 residents in 46 Residential Care Homes for the Elderly from February to May 2014. A total of 105 residents had at least one type of infection based on the survey definition. The overall prevalence of all infections was $2.7 \%$ (95\% confidence interval, $2.2 \%-3.4 \%$ ). The three most common infections were of the respiratory tract $(1.3 \%$; 95\% confidence interval, $0.9 \%-1.9 \%)$, skin and soft tissue $(0.7 \%$; $95 \%$ confidence interval, $0.5 \%-1.0 \%)$, and urinary tract $(0.5 \%$; $95 \%$ confidence interval, $0.3 \%-0.9 \%)$. Total dependence in activities of daily living, as indicated by low Barthel Index score of 0 to 20 (odds ratio $=3.0 ; 95 \%$ confidence interval, 1.4-6.2), and presence of a wound or stoma (odds ratio $=2.7 ; 95 \%$ confidence interval, 1.4-4.9) were significantly associated with presence of infection.

Conclusions: This survey provides information about infections among residents in Residential Care Homes for the Elderly in the territory. Local data enable us to understand the burden of infections and formulate targeted measures for prevention.

\author{
Hong Kong Med J 2016;22:347-55 \\ DOI: 10.12809/hkmj164865 \\ ${ }^{1}$ CSM Choy *, MB, BS \\ ${ }^{2}$ H Chen, MB, BS, FHKAM (Community Medicine) \\ ${ }^{3} \mathrm{CSW}$ Yau, MB, BS, FHKAM (Community Medicine) \\ ${ }^{2}$ EK Hsu, BSc, MSc \\ ${ }^{2}$ NY Chik, BNurs \\ ${ }^{2}$ ATY Wong, MB, BS, FHKAM (Medicine)
}

Accident and Emergency Department, Queen Elizabeth Hospital, Jordan, Hong Kong

2 Infection Control Branch, Centre for Health Protection, Hong Kong

${ }^{3}$ Surveillance and Epidemiology Branch, Centre for Health Protection, Hong Kong

* Corresponding author: carmencly@yahoo.com.hk

New knowledge added by this study

- Characteristics of local Residential Care Homes for the Elderly (RCHE) residents were explored. Most individuals had medical co-morbidities and required assistance with activities of daily living (ADL); use of an indwelling medical device was also common.

- Local prevalence of infections among residents in RCHE was $2.7 \%$ and the most common infection was of the respiratory tract.

- Total dependence in ADL and presence of a wound or stoma were associated with presence of infections among residents in RCHE in Hong Kong.

Implications for clinical practice or policy

- Measures that focus on prevention of respiratory tract infection among the elderly should be emphasised and an infection control programme should be designed to enhance such practice in RCHE.

- Infection control protocols can be developed according to specific areas of nursing care, for example, wound care or catheter care.

\section{Introduction}

Ageing is a worldwide phenomenon, and Hong Kong, without exception, is encountering the same population change. In 2014, the proportion of our elderly population aged 65 years or above was $15 \%$.
This proportion is expected to double over the next 20 years, to $28 \%$ in $2034 .^{1}$

In Hong Kong, Residential Care Homes for the Elderly (RCHEs) provide different levels of care for the elderly who-for personal, social, health, or 


\section{香港安老院舍點向感染率普查 蔡紹雯、陳虹、邱穗華、許諾、戚雅妍、黃天祐}

引言：研究香港安老院舍內院友常見感染病的感染率及相關風險因 素

方法：這項點向感染率普查透過分層單級整群抽樣方法選出安老院 舍。所有居住於被招募院舍的65歲或以上長者均有參與是次普查。是 次普查以統一的普查定義辨別感染病, 同時收集各院友的基本資料及 健康資料, 如病史、防疫紀錄、抗生素的使用和日常生活功能（以巴 氏指數評估），以找出與感染病相關的風險因素。

結果：是次普查於 2014 年 2 月至 5 月期間進行, 從46間安老院舍中收 集3857名院友的資料, 當中 105 名院友患有至少一種符合普查定義的 感染病。整體感染率為2.7\%（95\%置信區間2.2\%至3.4\%）。首三位 最常見之感染包括呼吸道感染（1.3\%；95\%置信區間0.9\%至1.9\%) 皮膚及軟組織感染（ $0.7 \% ； 95 \%$ 置信區間 $0.5 \%$ 至 $1.0 \%)$ 及尿道感染 （ $0.5 \% ； 95 \%$ 置信區間 $0.3 \%$ 至 $0.9 \%)$ 。此外, 日常生活功能屬完全 依賴, 即被評估為低巴氏指數0-20（風險比 $3.0 ； 95 \%$ 置信區間 1.4 至 6.2 ) 及長者有傷口或造口（風險比 $2.7 ； 95 \%$ 置信區間 1.4 至 4.9 ）均與 院友出現感染有關。

結論：是次普查提供有關本地安老院舍院友的感染病資料。本地數據 有助了解感染病所造成之負擔, 從而能更有效制定針對預防感染的方 案。 as well as the consequence of functional impairment among RCHE residents, leading to a reduction in their quality of life. ${ }^{4}$

Local studies of infectious diseases in the RCHE setting are scarce. The last such survey was conducted in 2006. ${ }^{5}$ Continuous or regular surveillance serves to reveal the disease burden to increase awareness of infections and to identify critical areas for infection control. It is important that we understand the local epidemiology and burden of infections among $\mathrm{RCHE}$ residents and apply measures to control these infections and safeguard the health of this vulnerable group.

\section{Methods}

We conducted a point prevalence survey of common infections among residents of RCHEs in Hong Kong.

\section{Population and setting}

All RCHEs in Hong Kong were included. All residents aged 65 years or above who were present at 9 am (the reference time) on the survey day were included. Residents were excluded from the survey if: (1) he/ she was not present at the reference time (owing to medical appointment, admission to hospital, or home leave from the RCHE); or (2) he/she attended the RCHE as a day patient/resident. family. These RCHEs can be broadly categorised as private homes $(\mathrm{PH})$ and non-private homes $(\mathrm{NPH})$; the former are run by private entrepreneurs and vary in size and capacity, while the latter are run by non-governmental organisations and include care and attention homes for the elderly and subvented, and self-financing and contract homes that provide subsidised care for the elderly. In 2015, there were around 740 RCHEs providing over 73000 residential placements over the territories and residential care for approximately $7 \%$ of the elderly in Hong Kong. ${ }^{1,2}$ These numbers are expected to increase further.

Generally speaking, RCHEs are very heterogeneous in terms of size, facilities, manpower, and level of care. Some residents are encouraged to participate in various types of group activities while some residents may require assistance in daily activities. These activities, together with the confined and shared living environment, may promote the transmission of infectious diseases.

Infections are an important cause of morbidity and mortality among the elderly, and place a significant burden on our health care system. Residents of RCHEs are usually frail; compared with their community-dwelling counterparts, they are more susceptible to infections and related complications. Overseas studies conducted in a hospital setting have shown that the mortality rate of community-acquired pneumonia is $30 \%$, while that in nursing homes is substantially higher, with a reported rate of up to $57 \% .^{3}$ Infections may be a cause

\section{Sampling strategy}

A list of all RCHEs in Hong Kong was retrieved from the Social Welfare Department website. ${ }^{6}$ All RCHEs on the list were stratified according to the main geographical region of Hong Kong (Kowloon, Hong Kong Island, and New Territories) and type of RCHE (PH and NPH) into six strata. Stratified single-stage cluster random sampling was performed using the captioned list as the sampling frame. All residents were surveyed in each recruited home.

\section{Data collection}

The survey was conducted from February to May 2014. A survey team comprising doctors, nurses, and research staff visited the RCHEs for data collection on any one day during the survey period. A standardised survey form was developed based on a previous similar prevalence survey. ${ }^{5}$ This survey form comprised four parts: (1) socio-demographic information about the resident; (2) health information including medical history, vaccination history, and antibiotic use; (3) measurement of activities of daily living (ADL) using the Barthel Index $(\mathrm{BI})^{7}$; and (4) a checklist of acute symptoms of common infections. Symptoms of acute infections were obtained by doctors by interviewing the residents or their major carers with the help of RCHE staff. All health-related information was verified by doctors or nurses; functional status of residents was assessed by trained 
nurses using the BI.

A pilot study was conducted in two RCHEs in February 2014 to field test the data collection tools. Inter-rater reliability on BI was assessed during the period for the six trained nurses. Cohen's kappa of BI estimated ranged from 0.8 to 1 , suggesting good inter-rater reliability among them.

The survey was conducted in an anonymous manner. Written consent was obtained from the RCHEs. Verbal consent was obtained from residents and/or their relatives. If any residents (or their relatives) refused to participate in the survey, their information was not retrieved. If relevant data were not available on the survey day, data would be retrieved within 1 week. The study was approved by the Ethics Committee of the Department of Health.

\section{Outcome measures}

Infection was defined using any one of the following criteria: (1) presence of symptoms and/or signs of infection that developed in the 24 hours preceding the survey day, that fulfilled the surveillance criteria of the Canadian Consensus Conference ${ }^{8}$; (2) infection diagnosed by a locally registered physician (eg visiting medical officers, general practitioners); or (3) consumption of antimicrobial agents on the survey day for a specific infection.

\section{Sample size and power estimation}

Sample size was estimated to determine the prevalence of infections among residents in RCHEs in Hong Kong. Based on a previous prevalence survey in Hong Kong, 5 the prevalence of infections was $5.7 \%$, the design effect (DEFF) was 1.765 with an intraclass correlation coefficient (ICC) of 0.025 and average cluster size of 31.61. Assuming the margin of error to be 0.2 , given a conservative DEFF of 2 , the sample size calculated was 3178 .

\section{Statistical analyses}

$\mathrm{R}$ (version 3.0.2) was used for statistical analysis. "Survey" package (version 3.29-5) in $\mathrm{R}$ was used to calculate the prevalence of infections adjusted for cluster sampling. Prevalence rates of infections and other study variables were calculated using "svyciprop" function from the "Survey" package. Logistic regression with adjustment on cluster sampling was performed using "svyglm" function from the "Survey" package to identify risk factors for infection. Variables were included for multivariate analysis if: (1) the $P$ value was $<0.25$ in univariate analysis or (2) the variables had been considered as risk factors of infection in previous studies, such as mobility status, use of medical devices, presence of wound, home size, gender, and recipient of the Comprehensive Social Security Assistance (as a surrogate measurement of social economic status). ${ }^{9-12}$ In addition, subgroup analyses were performed to explore the association of specific risk factors with different types of infection, such as the presence of chronic obstructive pulmonary disease (COPD) with respiratory tract infection (RTI) and diabetes mellitus (DM) with skin and soft tissue infection (SSTI). In order to adjust for multiple comparisons, $\mathrm{P}$ values calculated for exploration of association between risk factors and different types of infection were adjusted using Bonferroni correction. A P value of $<0.05$ was considered to be statistically significant.

\section{Results}

A total of 100 RCHEs were invited. The overall response rate was $46 \%(n=46)$. Table 1 illustrates the number of recruited RCHEs stratified by region and home type. A higher response rate was noted in NPHs $(70.6 \%, n=12)$ than PHs $(42.2 \%, n=35)$. The ICC and DEFF calculated from the sample collected were 0.0035 and 1.45 , respectively. The mean home capacity of the participating RCHEs was 111 residents per home (95\% confidence interval [CI], 88-133 residents per home) with a median occupancy of $89 \%$. Among the staff in participating RCHEs, $45.9 \%$ were personal care workers, $14.7 \%$ were health care workers, and $11 \%$ were nurses

TABLE I. Recruitment of Residential Care Homes for the Elderly (RCHEs)

\begin{tabular}{lcccc}
\hline Region & RCHE type & Total No. of RCHEs & No. (\%) of RCHEs invited & No. (\%) of RCHEs recruited† \\
\hline Hong Kong Island & Non-private & 32 & $4(12.5)$ & $2(50.0)$ \\
& Private & 138 & $32(23.2)$ & $8(25.0)$ \\
Kowloon & Non-private & 49 & $6(12.2)$ & $4(66.7)$ \\
& Private & 199 & $23(11.6)$ & $13(56.5)$ \\
New Territories & Non-private & 98 & $7(7.1)$ & $6(85.7)$ \\
& Private & 231 & $28(12.1)$ & $13(46.4)$ \\
Total & & $\mathbf{7 4 7}$ & $\mathbf{1 0 0 ( 1 3 . 4 )}$ & $\mathbf{4 6}(\mathbf{4 6 . 0 )}$ \\
\hline
\end{tabular}

* \% = No. of RCHEs invited / total No. of RCHEs

$\dagger \%=$ No. of RCHEs recruited $/$ No. of RCHEs invited 
(including registered nurses and enrolled nurses). There was no significant difference in terms of home capacity, occupancy, or staffing level between participating and non-participating RCHEs based on data from the annual assessment of all RCHEs conducted by Elderly Health Service, Department of Health.

\section{Demographics and underlying co-morbidity of residents}

Among the 4127 residents in the participating RCHEs, 261 (6.3\%) were excluded from the survey as they were not available due to hospitalisation, medical appointment, home leave, or other personal reasons. All 3866 residents who were at the participating RCHEs at 9 am on the survey day were invited and joined the survey. Nine $(0.2 \%)$ residents were not included in the analysis as their RCHEs failed to provide relevant information subsequently. Among the 3857 residents surveyed, the mean age was 85.2 years, and the female-to-male ratio was 1.9:1. Most residents were Chinese $(99.8 \%, \mathrm{n}=3849)$, and $56.5 \%$ $(n=2178)$ of those surveyed were above 84 years old. The mean age of male and female residents was 82.4 and 86.8 years, respectively. Table 2 shows the demographic information of the surveyed sample. Duration of their stay in RCHEs varied; a quarter had resided in a RCHE for less than 1 year, $29.4 \%$ for 1 to 3 years, $24.7 \%$ for 3 to 6 years, and $20.9 \%$ for more than 6 years. For ADL of residents, the median BI score was 30 , and $46.7 \%$ of residents scored 0-20 indicating they were totally dependent in ADL. ${ }^{13}$ Regarding use of an indwelling medical device, $14.4 \%$ of residents required at least one device, mostly a nasogastric tube $(9.2 \%)$ or urinary catheter $(5.3 \%)$. Up to $75.8 \%$ of residents received the $2013 / 2014$ seasonal influenza vaccine and $50.2 \%$ had received the pneumococcal vaccine. Most residents $(87.1 \%)$ had more than one underlying co-morbidity with the most common diagnosis being hypertension (69.3\%), followed by dementia (37.0\%) and stroke (35.0\%) [Table 3].

\section{Prevalence of infections}

A total of 105 residents were diagnosed with at least one infection based on the survey definition. Among these residents, 102 had one type of infection and three had two types of infection. The overall prevalence of infections was $2.7 \%$ (95\% CI, 2.2\%$3.4 \%)$. Table 4 shows the prevalence of different infections.

Of all the infections, RTI was the most common type, comprising $49.1 \% \quad(n=53)$ of all infections, followed by SSTI $(25.0 \%, \mathrm{n}=27)$ and urinary tract infection (UTI) [17.6\%, n=19; Fig].

\section{Factors associated with infectious diseases}

Table 5 illustrates factors associated with presence of
TABLE 2. Demographic information of surveyed sample at baseline

\begin{tabular}{cr}
\hline Demographics & $\begin{array}{c}\text { No. }\left(\%{ }^{*} \text { of }\right. \\
\text { residents }(\mathbf{n}=3857)\end{array}$ \\
\hline Age (years) & \\
$65-74$ & $374(10.0)$ \\
$75-84$ & $1305(34.0)$ \\
$85-94$ & $1766(45.5)$ \\
$\geq 95$ & $412(10.5)$
\end{tabular}

Gender

Female 2515 (64.9)

Male 1342 (35.1)

Home type

Non-private homes

$1170(28.7)$

Private homes

2687 (71.3)

Ethnicity

Chinese

3849 (99.8)

Non-Chinese

$8(0.2)$

Length of stay in RCHE (years)

$\leq 1$

958 (25.0)

$>1$ to $\leq 3$

$1142(29.4)$

$>3$ to $\leq 6$

$950(24.7)$

$>6$

807 (20.9)

Barthel Index

0-20 $1791(46.7)$

$21-40 \quad 435(11.1)$

41-60 $294(7.5)$

$61-80 \quad 320(8.1)$

81-100 1017 (26.6)

Use of medical device

Nasogastric tube $\quad 350$ (9.2)

Urinary catheter 207 (5.3)

Peritoneal dialysis $9(0.3)$

Tracheostomy $7(0.2)$

PEG tube $6(0.1)$

Suprapubic catheter $1(0.03)$

Others $10(0.2)$

Presence of wound and stoma

Surgical wound $6(0.1)$

Bedsore $97(2.5)$

lleostomy $4(0.1)$

Colostomy $37(0.9)$

Other wounds $\quad 117$ (3.0)

Vaccination

Influenza vaccine 2013/2014 2928 (75.8)

Pneumococcal vaccine

$1942(50.2)$

Abbreviations: PEG = percutaneous endoscopic gastrostomy; $\mathrm{RCHE}=$ Residential Care Home for the Elderly

* \% Rates presented were adjusted for the sampling method 
TABLE 3. Common co-morbidities of the study population

\begin{tabular}{lc}
\hline Co-morbidity & No. $\left(\%^{*}\right)$ of residents \\
\hline Hypertension & $2681(69.3)$ \\
Dementia & $1442(37.0)$ \\
Stroke & $1344(35.0)$ \\
Diabetes mellitus & $1115(28.5)$ \\
Depression & $250(6.4)$ \\
Schizophrenia & $112(3.0)$ \\
\hline
\end{tabular}

* \% Rates presented were adjusted for the sampling method

any infection and specific infections. Residents with ADL dependency, as reflected by low BI score of 0 -20 (odds ratio $[\mathrm{OR}]=3.0 ; 95 \% \mathrm{CI}, 1.4-6.2$ ), presence of a wound or stoma $(\mathrm{OR}=2.7 ; 95 \% \mathrm{CI}, 1.4-4.9)$, or co-morbidities including cardiovascular diseases (CVD) $[\mathrm{OR}=2.4 ; 95 \% \mathrm{CI}, 1.4-4.0]$ and respiratory diseases $(\mathrm{OR}=2.6$; 95\% CI, 1.6-4.1) were significantly likely to have an infection. Seasonal influenza vaccination $(\mathrm{OR}=0.82 ; \mathrm{P}=0.452)$ and pneumococcal vaccination $(\mathrm{OR}=0.66 ; \mathrm{P}=0.201)$ were associated with a lower risk of infection but neither reached statistical significance.

Subgroup analysis by site of infection showed that low BI score $(\mathrm{OR}=2.6 ; 95 \% \mathrm{CI}, 1.3-5.2)$ and COPD (OR=3.7; 95\% CI, 1.5-9.1) were significantly associated with RTI. Factors significantly associated with SSTI included low BI score $(\mathrm{OR}=5.5$; 95\% CI, 1.7-17.5), presence of wound(s) and stoma (OR=9.0; 95\% CI, 4.7-17.1), having DM (OR=1.9; 95\% CI, 1.0-3.6), mental illness ( $\mathrm{OR}=3.7$; 95\% CI, 1.2-11.8), and CVD (OR=4.6; 95\% CI, 1.3-16.3). Presence of a urinary catheter was significantly associated with UTI (OR=5.6; 95\% CI, 1.9-16.2).

\section{Discussion}

This point prevalence survey aimed to investigate the prevalence of infections among residents living in RCHEs in Hong Kong. It is essential to understand that this specific group of elderly differs significantly from their community-dwelling counterparts in terms of health condition, level of mobility, daily routine behaviour, and level of care received. The confined living environment, shared bathing equipment, group dining facilities, and close human-to-human contact potentially foster the transmission of infection. A local study has shown that nursing home residency is an independent predictor of infection-related mortality, pneumoniarelated mortality, and all-cause mortality. ${ }^{14}$

In this study, the overall prevalence of infections was $2.7 \%$. Among all infections, RTI, SSTI, and UTI ranked top with a prevalence of $1.3 \%, 0.7 \%$, and $0.5 \%$, respectively. Low BI score of $0-20$, presence
TABLE 4. Prevalence of different types of infections among residents of Residential Care Homes for the Elderly

\begin{tabular}{|lcc|}
\hline & No. of cases & Prevalence (95\% Cl) [\%] \\
\hline All infections & 105 & $2.71(2.15-3.42)$ \\
\hline Respiratory tract infectiont & 53 & $1.33(0.93-1.89)$ \\
\hline Pharyngitis & 27 & $0.66(0.35-1.23)$ \\
\hline Bronchitis or tracheobronchitis & 16 & $0.41(0.21-0.78)$ \\
\hline Influenza-like illness & 7 & $0.19(0.08-0.43)$ \\
\hline Pneumonia & 5 & $0.13(0.05-0.31)$ \\
\hline Upper respiratory tract infection & 5 & $0.13(0.05-0.38)$ \\
\hline Tuberculosis & 2 & $0.04(0.01-0.17)$ \\
\hline Skin and soft tissue infection & 27 & $0.70(0.47-1.04)$ \\
\hline Cellulitis & 20 & $0.51(0.30-0.85)$ \\
\hline Herpes & 3 & $0.08(0.02-0.24)$ \\
\hline Fungal infection & 2 & $0.06(0.02-0.22)$ \\
\hline Scabies & 2 & $0.05(0.01-0.20)$ \\
\hline Urinary tract infection & 19 & $0.53(0.32-0.86)$ \\
\hline Eye, ear, nose, and mouth infection & 7 & $0.20(0.09-0.41)$ \\
\hline Conjunctivitis & 4 & $0.11(0.05-0.27)$ \\
\hline Ear infection & 1 & $0.02(0.00-0.16)$ \\
\hline Gingivitis & 1 & $0.03(0.00-0.20)$ \\
\hline Uncategorised & 1 & $0.03(0.00-0.19)$ \\
\hline Gastrointestinal tract infection & 1 & $0.03(0.00-0.19)$ \\
\hline Systemic infection & 1 & $0.02(0.00-0.16)$ \\
\hline
\end{tabular}

Abbreviation: $\mathrm{Cl}=$ confidence interval

* \%ates presented were adjusted for the sampling method

45 Residents had one type, seven had two types, and one had three types of respiratory tract infections diagnosed

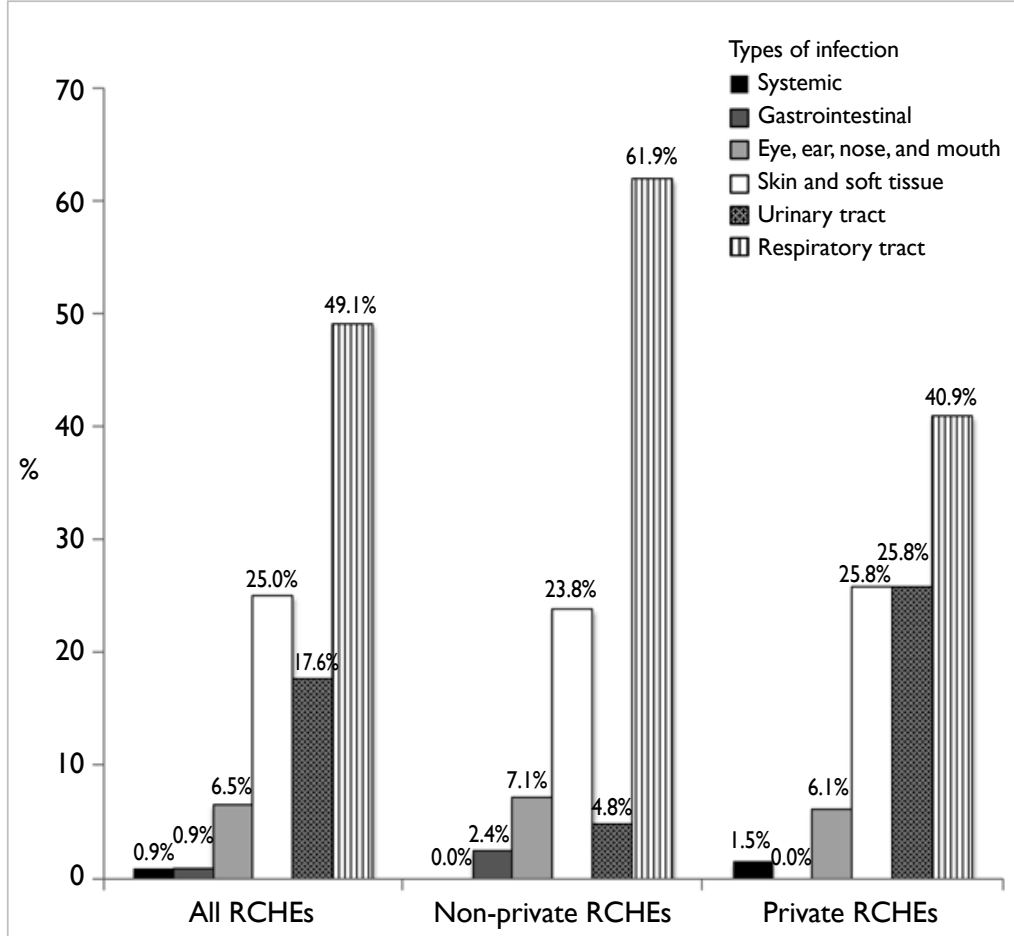

FIG. Distribution of different types of infections in Residential Care Homes for the Elderly (RCHEs) 
TABLE 5. Association between presence of infections and RCHEs/resident characteristics

\begin{tabular}{|c|c|c|c|c|c|c|}
\hline & \multicolumn{2}{|c|}{ Infection } & \multicolumn{2}{|c|}{ Univariate analysis } & \multicolumn{2}{|c|}{ Multivariate analysis } \\
\hline & Yes & No & OR $(95 \% \mathrm{Cl})$ & P value & OR (95\% Cl) & $P$ value \\
\hline \multicolumn{7}{|c|}{ RCHE characteristics } \\
\hline \multicolumn{7}{|l|}{ Home type } \\
\hline Non-private & 41 & 1129 & Reference & - & Reference & - \\
\hline Private & 64 & 2623 & $0.70(0.41-1.21)$ & 0.209 & $0.67(0.35-1.29)$ & 0.242 \\
\hline \multicolumn{7}{|c|}{ Home capacity (No. of residents accommodated) } \\
\hline$\leq 70$ & 20 & 892 & Reference & - & Reference & - \\
\hline$>70$ & 85 & 2860 & $1.36(0.70-2.63)$ & 0.375 & $1.40(0.72-2.71)$ & 0.330 \\
\hline \multicolumn{7}{|c|}{ Residents' characteristics } \\
\hline \multicolumn{7}{|l|}{ Gender } \\
\hline Female & 64 & 2451 & Reference & - & Reference & - \\
\hline Male & 41 & 1301 & $1.18(0.80-1.75)$ & 0.401 & $1.20(0.84-1.73)$ & 0.332 \\
\hline \multicolumn{7}{|c|}{ Age-group (years) } \\
\hline $65-74$ & 4 & 370 & Reference & - & Reference & - \\
\hline $75-84$ & 40 & 1265 & $2.89(0.97-8.64)$ & 0.065 & $2.71(0.91-8.03)$ & 0.086 \\
\hline $85-94$ & 50 & 1716 & $2.60(0.73-9.29)$ & 0.151 & $2.27(0.66-7.76)$ & 0.206 \\
\hline$\geq 95$ & 11 & 401 & $2.64(0.67-10.44)$ & 0.176 & $2.09(0.54-8.02)$ & 0.294 \\
\hline \multicolumn{7}{|l|}{ CSSA } \\
\hline No & 41 & 1504 & Reference & - & Reference & - \\
\hline Yes & 64 & 2248 & $1.06(0.74-1.52)$ & 0.767 & $1.12(0.77-1.61)$ & 0.568 \\
\hline \multicolumn{7}{|l|}{ Barthel Index } \\
\hline $81-100$ & 13 & 1004 & Reference & - & Reference & - \\
\hline $61-80$ & 8 & 312 & $1.93(0.83-4.53)$ & 0.137 & $1.60(0.66-3.85)$ & 0.306 \\
\hline $41-60$ & 5 & 289 & $1.50(0.43-5.19)$ & 0.527 & $1.30(0.36-4.61)$ & 0.693 \\
\hline $21-40$ & 10 & 425 & $2.01(0.90-4.47)$ & 0.097 & $1.78(0.76-4.20)$ & 0.201 \\
\hline $0-20$ & 69 & 1722 & $3.37(1.71-6.61)$ & 0.001 & $2.96(1.41-6.23)$ & 0.009 \\
\hline \multicolumn{7}{|c|}{ Presence of indwelling medical device } \\
\hline No & 80 & 3219 & Reference & - & Reference & - \\
\hline Yes & 25 & 533 & $1.97(1.14-3.40)$ & 0.020 & $1.29(0.68-2.42)$ & 0.442 \\
\hline \multicolumn{7}{|c|}{ Presence of wound or stoma } \\
\hline No & 86 & 3520 & Reference & - & Reference & - \\
\hline Yes & 19 & 232 & $3.40(1.86-6.23)$ & $<0.001$ & $2.65(1.43-4.94)$ & 0.005 \\
\hline \multicolumn{7}{|c|}{ 2013-2014 Seasonal influenza vaccine } \\
\hline No & 31 & 898 & Reference & - & Reference & - \\
\hline Yes & 74 & 2854 & $0.72(0.51-1.02)$ & 0.071 & $0.82(0.49-1.37)$ & 0.452 \\
\hline \multicolumn{7}{|c|}{ Pneumococcal vaccine } \\
\hline No & 59 & 1856 & Reference & - & Reference & - \\
\hline Yes & 46 & 1896 & $0.74(0.50-1.10)$ & 0.142 & $0.66(0.35-1.23)$ & 0.201 \\
\hline \multicolumn{7}{|c|}{ Resident's underlying medical conditions } \\
\hline \multicolumn{7}{|c|}{ Cardiovascular disease } \\
\hline No & 14 & 896 & Reference & - & Reference & - \\
\hline Yes & 91 & 2856 & $2.15(1.25-3.67)$ & 0.008 & $2.36(1.40-3.99)$ & 0.004 \\
\hline \multicolumn{7}{|c|}{ Respiratory disease } \\
\hline No & 86 & 3439 & Reference & - & Reference & - \\
\hline Yes & 19 & 313 & $2.20(1.43-3.40)$ & $<0.001$ & $2.58(1.61-4.13)$ & $<0.001$ \\
\hline \multicolumn{7}{|c|}{ Malignant neoplasm } \\
\hline No & 96 & 3560 & Reference & - & Reference & - \\
\hline Yes & 9 & 192 & $1.74(0.71-4.28)$ & 0.233 & $1.67(0.62-4.53)$ & 0.325 \\
\hline
\end{tabular}

Abbreviations: $\mathrm{Cl}$ = confidence interval; CSSA = Comprehensive Social Security Assistance; OR = odds ratio; RCHEs = Residential Care Homes for Elderly 
of a wound or stoma, and co-morbidities including CVD and respiratory diseases were significantly associated with presence of infection.

Compared with the previous prevalence survey of infections among residents of RCHEs in Hong Kong conducted in November 2006, ${ }^{5}$ a lower overall prevalence was noticed in this survey. In 2006 the prevalence was $5.7 \% .{ }^{5} \mathrm{~A}$ similar pattern of prevalence regarding type of infection was observed for common cold or pharyngitis (included under RTI in our study) that was the most common type of infection, followed by SSTI and UTI. This reduction in overall prevalence over a 6-year period may be due to a better awareness of infection control among the general public and health care workers, particularly after the severe acute respiratory syndrome endemic in 2003 and H1N1 swine influenza endemic in 2009. Another encouraging finding in this study may also account for this improved trend: an increased uptake of seasonal influenza vaccine was noted, from $60.3 \%$ in year 2012-2013 to $75.8 \%$ in year 2013-2014 among surveyed residents.

Prevalence surveys conducted in long-term care facilities (LTCF) overseas have generally reported an overall higher prevalence of infection, from $3.4 \%$ to $11.8 \% .{ }^{15-24}$ Most reported UTI as the most common type of infection. ${ }^{15,16,19-23}$ Despite a lower prevalence in our survey compared with overseas surveys, we must interpret the results with caution for a few reasons. First, the difference in survey method, study population, and case definition among these studies may render direct comparison of prevalence inappropriate. Second, it is important to understand the differences between settings and the elderly population in LTCF in Hong Kong and those overseas. In the US, LTCF can further be categorised into veteran care centres that provide care for elderly military officers, and nursing homes and residential care communities that offer different levels of assistance in ADL depending on the elderly individual's capacity for self-care. ${ }^{25}$ On the contrary, in Europe, more than two thirds of those receiving institutional care are above 80 years of age. ${ }^{26}$ Third, staff levels, occupancy, ${ }^{25}$ local infection practice and guidelines, and accessibility to health care facilities, such as emergency room or secondary health care facilities in overseas LTCF differ significantly from our local setting. These factors may explain the difference in prevalence between local RCHEs and overseas LTCF.

This study also investigated the risk factors associated with the presence of infection among residents. Low BI score of 0-20 representing total dependency in ADL, and presence of a wound or stoma were associated with presence of any type of infection. The findings are consistent with past studies that suggest limitations in ADL or functional impairment, and presence of skin ulcers are risk factors for infection. ${ }^{15,17,21}$ Nevertheless, the protective effect of immunisation with seasonal influenza vaccine and pneumococcal vaccine was not clearly demonstrated in this study.

Regarding RTI, which essentially includes upper tract infections (eg common cold or influenza-like illness) and lower tract infections (eg pneumonia), COPD and lower BI score of 0 -20 were two associated factors. A few previous studies that focused on risk factors for pneumonia (or specifically nursing home-associated pneumonia) also suggested that a low BI score, ${ }^{27}$ low ADL score, ${ }^{27}$ profound debility (measured by Karnofsky score of $\leq 40$ ), ${ }^{28}$ and $\mathrm{COPD}^{5,28}$ are associated factors, and is compatible with our findings.

Although multiple factors were significantly associated with SSTI in our study, including low BI score, presence of wounds and stoma, co-morbidities like DM, mental illnesses and CVD, limited studies have determined risk factors for SSTI in LTCF. In Cotter et al's study, ${ }^{16}$ presence of a urinary catheter, vascular catheter, pressure sores, or other wounds was significantly associated with SSTI. It is possible that individuals with DM or CVD are more prone to development of an ulcer or poor wound healing, and thus have a higher risk of SSTI. Further studies may be necessary to delineate the association between SSTI and other co-morbidities.

Presence of an indwelling urinary catheter is not surprisingly associated with UTI, and is compatible with the previous local study ${ }^{5}$ and most overseas studies. ${ }^{16,29,30}$ This reflects the importance of proper care for indwelling urinary catheters in RCHEs.

Our study provides more information regarding prevalence and risk factors associated with infectious diseases in RCHEs in Hong Kong. Readers, however, must take note of a few limitations of this study.

First, a point prevalence study offers only a snapshot of events and thus a causal relationship between risk factors and infections cannot be established. Our study was conducted during February to May, which was late winter to early spring time in Hong Kong, and the prevalence of different infections may have a seasonal variation, for example, influenza. ${ }^{31,32}$ Comparison needs to take account of the season during which the study was conducted.

Second, only 46 of the 100 invited RCHEs participated in the survey. This response rate may affect the generalisability of results. It is possible that the RCHEs with stronger compliance with infection control measures volunteered to participate whilst those homes that refused were less compliant and had a higher infection prevalence.

Third, the exclusion of residents who were not present at the RCHEs at the reference time may have 
led to underestimation of the prevalence of infection. We reviewed the list of residents excluded from the survey and found 18 of them had been admitted to hospital in the 2 days preceding the survey, of whom 10 were admitted because of symptoms or signs suggestive of infection. Assuming they all fulfilled the criteria for infection in this survey, the effect was likely minimal, with an adjusted prevalence of infections of $2.9 \%$ (95\% CI, 2.3\%-3.7\%).

Fourth, demographic data, medical history, and vaccination history were retrieved from records maintained by RCHEs, but different RCHEs had different practices of record keeping. Data may have been incomplete or inadequate in certain RCHEs while others may have provided more detailed data. These differences were minimised by a standard protocol and training of the survey team and verification of data with RCHE staff on site.

Finally, we did not include any infection control practice measures in our study, such as hand hygiene compliance of staff and environmental hygiene measures. While the aim of the study was not to assess the infection control practices of RCHEs, these factors could potentially affect the results in the risk factor analysis, and hence, readers should interpret the regression result in the context that confounding may present.

\section{Conclusions}

The overall prevalence of infections among $\mathrm{RCHE}$ residents was estimated to be $2.7 \%$. Associated factors were identified. It is recommended that infection control measures be targeted towards these factors. Training for RCHE staff and a policy to execute infection control guidelines in RCHEs should be planned early in view of an increasing demand for services provided by RCHEs. Further study can be carried out at different times of the year to identify any seasonal changes and pattern of infections, or targeted at residents admitted to public hospitals with acute infections to estimate the overall burden on our health care sector.

\section{Acknowledgements}

The authors would like to thank the survey team for their hard work in study design and fieldwork. Furthermore, we extend our heartfelt gratitude to all the participating RCHEs and their staff for their assistance throughout the study. Without their support, this survey would not have been possible. The authors would like to thank the Elderly Health Service, Department of Health for sharing their data on annual assessment of RCHEs.

\section{Declaration}

All authors have disclosed no conflicts of interest.

\section{References}

1. Census and Statistics Department, Hong Kong SAR Government. Hong Kong population projections 20152064. September 2015. Available from: http://www. statistics.gov.hk/pub/B1120015062015XXXXB0100.pdf. Accessed 22 Dec 2015.

2. Social Welfare Department, Hong Kong SAR Government. Provision of residential care services for elders (nongovernmental organisations versus private sector). March 2015. Available from: http://www.swd.gov.hk/doc/elderly/ ERCS/Overview\%20item(b)English(31-3-2015).pdf. Accessed 22 Dec 2015.

3. Gavazzi G, Krause KH. Ageing and infection. Lancet Infect Dis 2002;2:659-66.

4. Büla CJ, Ghilardi G, Wietlisbach V, Petignat C, Francioli P. Infections and functional impairment in nursing home residents: a reciprocal relationship. J Am Geriatr Soc 2004;52:700-6.

5. Chen H, Chiu AP, Lam PS, et al. Prevalence of infections in residential care homes for the elderly in Hong Kong. Hong Kong Med J 2008;14:444-50.

6. Social Welfare Department, Hong Kong SAR Government. List, licences and briefs of residential care homes. Available from: http://www.swd.gov.hk/en/index/site_pubsvc/page_ elderly/sub_residentia/id_listofresi/. Accessed 31 Dec 2013.

7. Mahoney FI, Barthel DW. Functional evaluation: The Barthel Index. Md State Med J 1965;14:61-5.

8. McGeer A, Campbell B, Emori TG, et al. Definitions of infection for surveillance in long-term care facilities. Am J Infect Control 1991;19:1-7.

9. Magaziner J, Tenney JH, DeForge B, Hebel JR, Muncie HL Jr, Warren JW. Prevalence and characteristics of nursing home-acquired infections in the aged. J Am Geriatr Soc 1991;39:1071-8.

10. Li J, Birkhead GS, Strogatz DS, Coles FB. Impact of institution size, staffing patterns, and infection control practices on communicable disease outbreaks in New York State nursing homes. Am J Epidemiol 1996;143:1042-9.

11. Cohen S. Social status and susceptibility to respiratory infections. Ann N Y Acad Sci 1999;896:246-53.

12. Harrington RD, Hooton TM. Urinary tract infection risk factors and gender. J Gend Specif Med 2000;3:27-34.

13. McDowell I. Measuring health: a guide to rating scales and questionnaires. Oxford: Oxford University Press; 2006.

14. Chan TC, Hung IF, Cheng VC, et al. Is nursing home residence an independent risk factor of mortality in Chinese older adults? J Am Geriatr Soc 2013;61:1430-2.

15. Chami K, Gavazzi G, Carrat F, et al. Burden of infections among 44,869 elderly in nursing homes: a cross-sectional cluster nationwide survey. J Hosp Infect 2011;79:254-9.

16. Cotter M, Donlon S, Roche F, Byrne H, Fitzpatrick F. Healthcare-associated infection in Irish long-term care facilities: results from the First National Prevalence Study. J Hosp Infect 2012;80:212-6.

17. Eriksen HM, Iversen BG, Aavitsland P. Prevalence of nosocomial infections and use of antibiotics in long-term care facilities in Norway, 2002 and 2003. J Hosp Infect 2004;57:316-20.

18. Moro ML, Mongardi M, Marchi M, Taroni F. Prevalence of long-term care acquired infections in nursing and residential homes in the Emilia-Romagna Region. Infection 2007;35:250-5. 
19. Lim CJ, McLellan SC, Cheng AC, et al. Surveillance of infection burden in residential aged care facilities. Med J Aust 2012;196:327-31.

20. Tsan L, Langberg R, Davis C, et al. Nursing home-associated infections in Department of Veterans Affairs community living centers. Am J Infect Control 2010;38:461-6.

21. Tsan L, Davis C, Langberg R, et al. Prevalence of nursing home-associated infections in the Department of Veterans Affairs nursing home care units. Am J Infect Control 2008;36:173-9.

22. Marchi M, Grilli E, Mongardi M, Bedosti C, Nobilio L, Moro ML. Prevalence of infections in long-term care facilities: how to read it? Infection 2012;40:493-500.

23. Dwyer LL, Harris-Kojetin LD, Valverde RH, et al. Infections in long-term care populations in the United States. J Am Geriatr Soc 2013;61:342-9.

24. European Centre for Disease Prevention and Control. Point prevalence survey of healthcare-associated infections and antimicrobial use in European long-term care facilities. May-September 2010. Available from: http://www.ecdc.europa.eu/en/publications/_layouts/ forms/Publication_DispForm.aspx?List=4f55ad51-4aed4d32-b960-af70113dbb90\&ID=1086. Accessed 31 Dec 2013.

25. Harris-Kojetin L, Sengupta M, Park-Lee E, Valverde R. Long-term care services in the United States: 2013 overview. Vital Health Stat 3 2013;(37):1-107.
26. Rodrigues R, Huber M, Lamura G, editors. Facts and figures on healthy ageing and long-term care. European Centre for Social Welfare Policy and Research; 2012. Available from: http://citeseerx.ist.psu.edu/viewdoc/download?doi=10.1.1 $.303 .1022 \&$ rep $=$ rep1\&type=pdf. Accessed 22 Jan 2016.

27. Wójkowska-Mach J, Gryglewska B, Romaniszyn D, et al. Age and other risk factors of pneumonia among residents of Polish long-term care facilities. Int J Infect Dis 2013;17:e37-43.

28. Muder RR. Pneumonia in residents of long-term care facilities: epidemiology, etiology, management, and prevention. Am J Med 1998;105:319-30.

29. Michel JP, Lesourd B, Conne P, Richard D, Rapin CH. Prevalence of infections and their risk factors in geriatric institutions: a one-day multicentre survey. Bull World Health Organ 1991;69:35-41.

30. Eriksen HM, Koch AM, Elstrøm P, Nilsen RM, Harthug $\mathrm{S}$, Aavitsland P. Healthcare-associated infection among residents of long-term care facilities: a cohort and nested case-control study. J Hosp Infect 2007;65:334-40.

31. Saha S, Chadha M, Al Mamun A, et al. Influenza seasonality and vaccination timing in tropical and subtropical areas of southern and south-eastern Asia. Bull World Health Organ 2014;92:318-30.

32. Yang L, Wong CM, Lau EH, Chan KP, Ou CQ, Peiris JS. Synchrony of clinical and laboratory surveillance for influenza in Hong Kong. PLoS One 2008;3:e1399. 